\title{
Morphological and Physiological Responses of Sugarcane to Leifsonia xyli subsp. xyli Infection
}

\author{
Xiaoqiu Zhang, Minghui Chen, Yongjian Liang, Yongxiu Xing, and Litao Yang, Agricultural College, State Key Laboratory of Subtropical \\ Bioresources Conservation and Utilization, Guangxi University, Nanning 530005, China; Minghui Chen, Ping Ding Shan University, Ping- \\ dingshan, Henan 46700, China; Jack C. Comstock, USDA-ARS, Sugarcane Field Station, Canal Point, FL; Yangrui Li, and Litao Yang, \\ Guangxi Key Laboratory of Sugarcane Genetic Improvement, Key Laboratory of Sugarcane Biotechnology and Genetic Improvement \\ (Guangxi), Ministry of Agriculture, Sugarcane Research Center, Chinese Academy of Agricultural Sciences; Sugarcane Research Institute, \\ Guangxi Academy of Agricultural Sciences, Nanning 530007, China
}

\begin{abstract}
Zhang, X., Chen, M., Liang, Y., Xing, Y., Comstock, J. C., Li, Y., and Yang, L. 2016. Morphological and physiological responses of sugarcane to Leifsonia xyli subsp. xyli infection. Plant Dis. 100:2499-2506.

Ratoon stunt, caused by the bacterium Leifsonia xyli subsp. xyli, is one of the major sugarcane diseases worldwide. The objectives of this study were to determine the variation in morphology and DNA sequence of L. xyli subsp. xyli strains isolated in China, to compare the changes that occurred in vascular ultrastructure and levels of endogenous hormone abscisic acid (ABA), auxins (indoleacetic acid [IAA]), and gibberellic acids $\left(\mathrm{GA}_{3}\right)$ in sugarcane stalks. Experiments were also conducted with two sugarcane varieties, 'ROC22' and 'Badila', in the greenhouse to understand the cytological and physiological mechanisms of $L$. xyli subsp. $x y l i$-induced growth stunting. There were three treatments in the experiments: (i) healthy plants (L. xyli subsp. xyli-free plants), (ii) infected plants $(L$. xyli subsp. $x y l i$-infected seedcanes treated with hot water, and (iii) infected plants (healthy seedcanes dipped in L. xyli subsp. xyli

cell culture). The results showed that sequence coverage of a locally isolated strain, LxxGXBZ01, was $99.99 \%$, and the average nucleotide identity between LxxGXBZ01 and the other well-characterized Brazilian isolate LxxCTCB07 was 93.61\%. LxxGXBZ01 occurred in different sizes and shapes in xylem vessels of infected plants. In comparison with healthy stalks, the secondary walls of the vessel element in $L$. xyli subsp. xyliinfected stalks were degraded with uneven wall thickness, deformities, sticky substances, and electron-dense substances accumulated inside the cells. Compared with the healthy and hot-water treatments, the contents of IAA and $\mathrm{GA}_{3}$ were significantly lower, while that of ABA was significantly higher in the $L$. $x y l i$ subsp. $x y l i$-infected stalks. The information obtained in this study will expand our understanding of ratoon stunt etiology and cytological and physiological bases of the disease manifestation.
\end{abstract}

Ratoon stunt, caused by the bacterium Leifsonia xyli subsp. xyli, is one of the most economically damaging diseases of sugarcane (Saccharum spp.) worldwide, with yield losses from near zero to $41 \%$, depending on the variety and growing conditions (Comstock 2002; Grisham 1991). Although the effect of ratoon stunt is more on ratoons (Gillaspie and Teakle 1989), 8 to 23\% yield loss is reported in the plant crop in Florida (Comstock 2002; Dean 1983).

Sugarcane is an important cash crop in Guangxi province of China, where the crop was planted on more than one million hectares and produced 8.56 million tons of sugar during the 2013-2014 milling season, which was $68 \%$ of total cane sugar produced in China. Its production is declining over years, due to various reasons, including ratoon stunt. Ratoon stunt was first reported in mainland China in 1986 (Wu and Huang 1986). Since then, it has been recorded in Guangxi and Yunnan of China, with incidence ranging from 10 to $100 \%$, depending on the production region ( $\mathrm{Li}$ et al. 2014).

L. xyli subsp. $x y l i$ is mechanically transmitted from infected plants to healthy plants (Hoy and Grisham 2006). The preferred ratoon stunt control methods in China are either seedcane heat treatment before planting, meristem tissue culture, which eliminates $L$. xyli subsp. xyli

Corresponding authors: Y. Li and L. Yang; Emails: liyr@gxaas.net and litao61@hotmail.com

X. Zhang and M. Chen contributed equally.

Nucleotide sequence data is deposited in the National Center for Biotechnology Information GenBank database under accession numbers LFYU00000000 and KR132244.

Accepted for publication 18 June 2016.

http://dx.doi.org/10.1094/PDIS-10-15-1134-RE

(C) 2016 The American Phytopathological Society in the seedcane setts, or both (Sheng et al. 2008). Although hot water treatment (HWT) $\left(50^{\circ} \mathrm{C}\right.$ for $2 \mathrm{~h}$ ) kills $L$. xyli subsp. xyli in sugarcane setts, it cannot completely eradicate the pathogen and may result in reduced emergence (Hoy and Flynn 2001). Meristem tissue culture can result in disease-free plants, which can be used as a source for micropropagation of disease-free plantlets (Comstock 2008). However, meristem tissue culture is time consuming and labor intensive. Loop-mediated isothermal amplification (Ghai et al. 2014), polymerase chain reaction (PCR) for pooled leaf sheath biopsies (LSB-PCR) (Young et al. 2014) and Taqman real-time PCR (Pelosi et al. 2013) have been developed as new detection methods of ratoon stunt in recent years. However, the development of resistant cultivars is the most promising method for disease management, which requires a full understanding of the mechanism of host specificity and pathogenicity for breeding programs and genetic modification.

L. xyli subsp. xyli is a nutritionally fastidious, slow growing, grampositive, and coryneform bacterium (Davis et al. 1980). In Brazil, L. xyli subsp. xyli (CTCB07) whole-genome sequencing was completed by Monteiro-Vitorello et al. (2004), which provided insights into its biology and pathogenicity. However, progress in understanding the molecular mechanism of host specificity and pathogenicity is very slow because the bacterium is difficult to grow in culture, and a highly ratoon stunt-resistant Saccharum officinarum L. clone has not been identified and little is known about the population structure of L. xyli subsp. xyli. Young et al. (2006) analyzed the 16S ribosomal RNA genes using DNA fingerprinting from infected sugarcane $L$. $x y l i$ subsp. xyli isolated from nine countries, including Australia, Brazil, Indonesia, Japan, Mali, Reunion (France), South Africa, the United States, and Zimbabwe, and found no sequence variation. However, it has not yet been reported if there is any difference between an isolate of L. $x y l i$ subsp. xyli from China and other countries.

There are no easily discernible symptoms other than stunting for ratoon stunt. $L$. xyli subsp. xyli colonizes the xylem vessels of sugarcane plant (Tiwari et al. 2012). L. xyli subsp. xyli-infected plants 
show reduced cane diameter and shortened internodes, which are the components of cane yield. Therefore, the decrease in stalk height and stalk thickness results in reduced stalk weight and subsequent yield losses in $L$. $x y l i$ subsp. xyli-infected plants. The main cause of the stunting symptom associated with ratoon stunt was suggested to be the physical plugging of the xylem vessels and the presence of $L$. xyli subsp. $x y l i$-bacteria in vascular cells, including vessels, lacunae, tracheids, and parenchyma cells in the nodal area in L. xyli subsp. xyliinfected sugarcane stalks, with no anatomical changes (Kao and Damann 1980). However, it is unclear how the internal structure constrains physiological processes.

Studies on the xylem connections between organs have been focused on water transport (Zwieniecki et al. 2003). With an established relationship between water stress and ratoon stunt (Rossler 1974), it is logical to investigate the role of plant hormones in pathogenesis and observed growth variation. Plant hormones including auxins (indoleacetic acid, IAA), cytokinins, and gibberellic acids $\left(\mathrm{GA}_{3}\right)$ are main growth regulators involved in plant cell proliferation, growth, and development, including stem elongation in vitro as well as in vivo (Matsubayashi et al. 1999; Yang et al. 2012). Our previous study indicated that the growth of sugarcane internodes could be the result of increased $\mathrm{GA}_{3}$ (Wu et al. 2009). Studies on other crops, including Arabidopsis thaliana, tomato (Solanum lycopersicum), and rice (Oryza sativa), have shown that $\mathrm{ABA}, \mathrm{GA}_{3}$, cytokinin, and IAA emerged as the critical modulators of plant-microbe interactions as well (Asselbergh et al. 2008; De Vleesschauwer et al. 2012; RobertSeilaniantz et al. 2007). However, there have been no reports on the response of endogenous hormone biology in sugarcane stalk in ratoon stunt-affected plants, and the physiological mechanism of ratoon stunt effect on sugarcane growth and yield remain unclear.

We undertook this study to determine the variation in morphology and genomic sequence in $L$. xyli subsp. xyli isolates from China and compared them with the previously reported $L$. xyli subsp. xyli isolates from other countries. Additionally, we studied the changes of endogenous hormones, vascular structure, and cytology associated with ratoon stunt development in sugarcane.

\section{Materials and Methods}

Plant materials and isolation of bacterial strain. The sugarcane cultivar Badila, which is highly susceptible to ratoon stunt but is a most important commercial chewing cane cultivar occupying $90 \%$ of the total commercial chewing cane area in China, was grown in the experimental field at the Agricultural College, Guangxi University, Nanning, China, and the infected plant was used for sample preparation. The second and third basal internodes were collected for L. xyli subsp. xyli isolation and detection with PCR (Pan et al. 1998), and they were disinfected with $70 \%$ alcohol and were peeled and cut into pieces of $1 \times 6 \mathrm{~cm}$ with a sharp knife, were placed into a sterilized 50-ml centrifuge tube, and were centrifuged at $1,200 \times g$ for $15 \mathrm{~min}$ at room temperature. The extracted sugarcane juice was collected, was filtered with $0.45-\mu \mathrm{m}$ membrane filter, and was placed on modified SC medium (compositions in 1 liter of distilled water: corn meal agar, $17 \mathrm{~g}$; Bacto-agar, $4 \mathrm{~g}$; Bacto-peptone, $8 \mathrm{~g}$; 0.1\% bovine hemin chloride solution in $0.05 \mathrm{M} \mathrm{NaOH}, 30 \mathrm{ml} ; \mathrm{MgSO}_{4}, 0.2 \mathrm{~g}$; $\mathrm{K}_{2} \mathrm{HPO}_{4}$ in $0.1 \mathrm{M}$ stock, $13 \mathrm{ml} ; \mathrm{KH}_{2} \mathrm{PO}_{4}$ in $0.1 \mathrm{M}$ stock, $87 \mathrm{ml}$; glucose, $2 \mathrm{~g}$; cysteine, free base, $0.5 \mathrm{~g}$; bovine serum albumin, fraction $\mathrm{V}, 2 \mathrm{~g}$. The glucose, cysteine, and bovine serum albumin were filtersterilized and were added to the autoclaved portion at $55^{\circ} \mathrm{C}$. The $\mathrm{pH}$ was adjusted to 7.5 with $10 \mathrm{M} \mathrm{NaOH}$ ) without any antibiotics by droplets, and was incubated at $28^{\circ} \mathrm{C}$ for 2 weeks or more for bacterium culture (Brumbley et al. 2002). The colony of bacterial strain observed on the plate was named LxxGXBZ01.

Morphological observation of LxxGXBZ01 under transmission electron microscopy (TEM). LxxGXBZ01 colonies were collected from the plates and were put into a $1.5-\mathrm{ml}$ tube. The cultured LxxGXBZ01 was negatively stained with $1 \%$ phosphotungstic acid and the cellular morphology of LxxGXBZ01 was observed under TEM (Hitachi H-7650). For thin-section observation, LxxGXBZ01 cells were collected by centrifugation at $6,000 \times g$ for $5 \mathrm{~min}$, followed by phosphate buffered solution (PBS) and deionized water washes, and were fixed in $3 \%$ glutaraldehyde for overnight. The cells were washed again with $0.1 \mathrm{M}$ PBS three times (each time for $15 \mathrm{~min}$ ), were refixed in $1 \%$ osmic acid for 1 to $2 \mathrm{~h}$, were dehydrated by ethanol, acetone, separately or in combination (respectively, 50, 70, 80, and $90 \%$ ethanol, mixture of $90 \%$ ethanol and $90 \%$ acetone [1:1], $90 \%$ acetone, and $100 \%$ acetone, 15 min each time), were saturated in the mixture of acetone and embedding medium (acetone/embedding medium, $1: 1$ for $1 \mathrm{~h}, 1: 3$ for 1 to $3 \mathrm{~h}$, and $0: 1$ for $2 \mathrm{~h}$ ), were embedded using epoxy resin 618 , and were polymerized $\left(35^{\circ} \mathrm{C}\right.$ for $15 \mathrm{~h}, 45^{\circ} \mathrm{C}$ for $12 \mathrm{~h}$, and $60^{\circ} \mathrm{C}$ for $24 \mathrm{~h}$ ). Finally, the cells were sectioned by a UC 7 ultra-microtome (Leica), were stained with uranium acetate-lead citrate, and were observed and photographed under the TEM.

Identifications of LxxGXBZ01 strain. The strain was identified as Leifsonia xyli subsp. xyli, using morphological and $16 \mathrm{~S}$ to $23 \mathrm{~S}$ ribosomal RNA intergenic spacer regions of the genomic DNA from the isolate, and the DNA of $L$. xyli subsp. xyli was used as positive control. The nucleotide sequence of strain LxxGXBZ01 is deposited in National Center for Biotechnology Information (NCBI) GenBank database under accession number LFYU00000000.

LxxGXBZ01 genome resequencing and analysis. The genomic DNA of strain LxxGXBZ01 was isolated with the DNA extraction kit (Beijing ComWin Biotech Co., Ltd.), following the manufacturer's instructions. The genome of LxxGXBZ01 was sequenced at BGI Shenzhen (http://www.genomics.cn), using the Illumina HiSEquation 2000 sequencing platform (Illumina). In order to obtain clean data, we discarded the reads of low-quality (those with three consecutive bases with quality $\leq \mathrm{Q} 20$ ) bases ( $40 \%$ as default, parameter setting at $36 \mathrm{bp}$ ), a certain proportion of Ns (10\% as default, parameter setting at $9 \mathrm{bp}$ ), adapter contamination ( $15 \mathrm{bp}$ overlap between adapter and reads as default, parameter setting at $15 \mathrm{bp}$ ), and duplication contamination. The short reads were assembled into a genome sequence using SOAPdenovo v2.04 with K-mer 23. Then, the assembly result was optimized according to paired-end and overlap relationship via mapping reads to contig. All sequencing reads obtained were aligned with the reference sequence of LxxCTCB07 with SOAPaligner v2.21, and the allowed aligning mismatch was set at five bases. The average sequencing depth and coverage ratio were calculated by using the alignment results. Single nucleotide polymorphism (SNP) and indel calling were based on the alignment between assembled result and reference, using MuMer 3.0 (http://mummer.sourceforge.net, default parameters) and LASTZ1.01.50 (http://www.bx.psu.edu/miller_lab/dist/README. lastz-1.02.00, default parameters), respectively. Average nucleotide identity (ANI) was calculated using EzBioclound (http://www.ezbiocloud. net/ezgenome/ani).

Experimental validation. To confirm the genomic variations in LxxGXBZ01, five variations (four SNPs and one indel) were selected for experimental validation. Primers were designed based on the sequences of the variation sites, using the software Primer Premier 5.0. The PCR products were analyzed with $1.0 \%$ agarose electrophoresis and, then, purified and sequenced using the Sanger platform (ABI, 3730XL). In the clone sequencing effort, at least five clones were sequenced for each sample. ExPASy (http://web.expasy. org/protparam/) and Motif scan (http://myhits.isb-sib.ch/cgi-bin/ motif_scan) were used to analyze the physical and chemical properties and functional domains of proteins, respectively, and Vector NTI10 was used to conduct amino acid sequence alignment.

Experimental treatments in the greenhouse. Two sugarcane cultivars, 'ROC22' and 'Badila', were used in the greenhouse experiment. 'ROC22' is the main commercial sugar cane cultivar, covering more than $60 \%$ of the total sugar cane-growing area in China and, also, susceptible to ratoon stunt with over 20 and $40 \%$ cane yield reduction in first and second ratoon crops, respectively, in commercial production. There were three treatments in the experiments: (i) healthy plants (L. xyli subsp. xyli-free sugarcane plants), (ii) infected plants (L. xyli subsp. xyli-infected seedcanes treated with hot water before inoculation at $50^{\circ} \mathrm{C}$ for $2 \mathrm{~h}$ ), and (iii) infected plants (healthy seedcanes were immersed in $10^{8} \mathrm{CFU} \cdot$ L. xyli subsp. xyli cell culture per milliliter). Three one-bud setts were planted in a pot $(35 \times 30 \mathrm{~cm})$, with 10 pots for each treatment, on March 12, 2012. The experiment was conducted in a greenhouse, with the regular water and fertilizer 
application for all treatments. For sampling, three representative main plants were cut from different pots in each replication each time. The DNA from sugarcane leaves and stalks was extracted with a DNA extraction kit (Beijing ComWin Biotech Co., Ltd.), according to manufacturer's instructions.

The infected and healthy plants were identified by PCR, following the method of Pan et al. (1998). The PCR was performed in a volume of $25 \mu \mathrm{l}$, containing $50 \mathrm{ng}$ DNA template, $0.4 \mu \mathrm{M}$, each, of forward and reverse primers, $12.5 \mu 12 \times$ Goldstar Taq master mix (a mixture of $T a q$ DNA polymerase, PCR buffer, $\mathrm{Mg}^{2+}$, and dNTPs, a product of Beijing ComWin Biotech Co., Ltd.), and sterile milli-Q water was added up to the final volume. The PCR program was carried out with initial denaturation at $95^{\circ} \mathrm{C}$ for $10 \mathrm{~min}, 40$ cycles of $95^{\circ} \mathrm{C}$ for $30 \mathrm{~s}$, $57^{\circ} \mathrm{C}$ for $30 \mathrm{~s}$, and $72^{\circ} \mathrm{C}$ for $1 \mathrm{~min}$, with a final $72^{\circ} \mathrm{C}$ extension for 5 min. An $8-\mu l$ aliquot of each amplified product was analyzed by electrophoresis on $1 \%$ agarose gels stained with GelRed (Biotium) to confirm the presence of a PCR product of the expected size.

Stalk tissue hormone extraction and assays. Two or three basal internodes of sugarcane plants grown for 90, 120, 150, and 180 days after shoot emergence were sampled for hormone analysis. One gram of the mixed fresh stalk tissue was ground into fine powder in the presence of liquid nitrogen, using mortar and pestle, was mixed with $2 \mathrm{ml}$ of $80 \%$ methanol (stored at $4^{\circ} \mathrm{C}$ before use) containing $1 \mathrm{mM}$ antioxidant ditertbutyl-p-cresol and the extraction mixture was maintained at $4^{\circ} \mathrm{C}$ for $4 \mathrm{~h}$. The mixture was centrifuged at $1,500 \times g$ for $15 \mathrm{~min}$ at $4^{\circ} \mathrm{C}$ (Dynamica Velocity 18R) and the supernatant was filtered through a C-18 solid phase extraction column. The filtrates were vacuum dried and dissolved in diluent solution (containing $0.1 \%$ Tween- 20 and $0.1 \%$ gelatin in phosphate-buffered solution, $\mathrm{pH}$ 7.5) for hormone assays.

IAA, $\mathrm{GA}_{3}$, and $\mathrm{ABA}$ concentrations in sugarcane stalk tissue were analyzed by enzyme-linked immune sorbent assays (ELISA) (Yang et al. 2001), using a hormone analysis kit (The Crop Chemical Control Laboratory at China Agricultural University, Beijing). Three biological replicates were used for hormone assays.

The assay was based on the linear equation taken from the value of $\mathrm{D}_{490}$ in standard sample. The natural logarithm of concentration expressed in abscissa and the value of Logit expressed in ordinate:

$$
\text { Logit }=\ln \left[\mathrm{B} /\left(\mathrm{B}_{\mathrm{o}}-\mathrm{B}\right)\right],
$$

where $B_{o}$ represents the value of $D_{490}$ with $0 \mathrm{ng} \cdot \mathrm{ml}^{-1}$, and $B$ represents the value of $\mathrm{D}_{490}$ with another concentration of standard sample.

After the hormone concentration in the extraction was calculated from the value of Logit, the hormone concentration $\left[\mathrm{w} /\left(\mathrm{ng} \cdot \mathrm{g}^{-1}\right)\right]$ in the plant was calculated as follows:

$$
\mathrm{W}=N \cdot \mathrm{V}_{2} \cdot \mathrm{V}_{3} \cdot \mathrm{B} /\left(\mathrm{V}_{1} \cdot \mathrm{m}\right),
$$

where $V_{1}$ represents the supernatant volume for concentration in vacuum drying, $V_{2}$ represents the total supernatant volume of the sample extraction, $V_{3}$ represents the sample volume for assay diluted from vacuum concentration, $\mathrm{m}$ represents the sample fresh weight, $\mathrm{N}$ is the mass concentration (ng. $\mathrm{ml}^{-1}$ ), and B represents the dilution factor for sample diluent constant volume.

Stalk slice preparation for infected stalk tissue and scanning electron microscopy (SEM) and TEM. Basal stalk tissue of 10month-old $L$. xyli subsp. xyli-infected sugarcane plants ('Badila') was trimmed to $5 \times 5 \mathrm{~mm}$ slices and was fixed in $3 \%$ glutaraldehyde for a minimum of $2 \mathrm{~h}$. After washing three times with $0.1 \mathrm{M}$ PBS, the slices were dehydrated by $50,70,80,90$, and $100 \%$ ethanol, followed by vacuum infiltration of hexamethyldisilazane for three times, and was then placed on the copper block for gold-plating. They were observed using scanning electron microscope (Tescan Vega 3, Chech) and the images were recorded. The TEM procedures of sugarcane stalk was the same as used for the morphological observation of LxxGXBZ01.

Data analysis. The data were collected and analyzed with the software SPSS 15.0.1 (Chicago) and Excel (2007). All statistical comparisons were considered significantly different at the $P<0.05$ level.

\section{Results}

Morphology and PCR verification of strain LxxGXBZ01. The colonies of LxxGXBZ01 were small white opalescent, circular, convex with entire margins, which were about $0.5 \mathrm{~mm}$ in diameter, after incubation on the modified SC medium for 4 weeks.

The LxxGXBZ01 cells under TEM were coryneform with smooth surface, atrichosis, and slightly swollen in the middle or end, different curves, and a few of ' $\mathrm{V}$ ' shape (Fig. 1A). The cell size was 0.16 to $0.32 \times 1.10$ to $3.20 \mu \mathrm{m}$ with septum formation (Fig. 1B). The ultrastructure of LxxGXBZ01 cells showed different sizes of bacteria and uneven cytoplasm, with structures of electron transparency, electrondense (ED) substances, mesosomes, and septum, which divided a cell into smaller parts (Fig. 1C).

Ten colonies were picked randomly for PCR to verify the $L . x y l i$ subsp. xyli strain. The results showed that the positive 438-bp fragment of $L$. xyli subsp. xyli was amplified from all the tested colonies, which confirmed that the isolated strain is Leifsonia xyli subsp. xyli, and the nucleotide sequence is submitted in the NCBI GenBank with the accession number KR132244.

Whole-genome resequencing of LxxGXBZ01 and comparison with LxxCTCB07. The genome sequencing of the LxxGXBZ01 strain was carried out with a new generation of high-throughput resequencing and $262 \mathrm{Mb}$ of data were produced with a 500-bp insert size. Based on assembly, the genome size was $2,446,908 \mathrm{bp}$, the GC content was $67.94 \%$, the number of scaffold was 82 , and the number of contig was 2,724 . A contig N50 (a measure of average length of contigs within the assembly) size of $1,088 \mathrm{bp}$ and a scaffold N50 size of 53,480 bp were obtained (Table 1). The resequencing result has been registered in GenBank with the accession number LFYU00000000. The results of comparative genomics analysis showed the coverage was $99.99 \%$ and the average depth was 130 . The ANI was $93.61 \%$ between the genomes of LxxCTCB07 (NCBI GenBank accession number is AE016822) and LxxGXBZ01, showing there was a high degree of similarity in the two L. xyli subsp. xyli isolates, as shown in Table 1. There were differences between
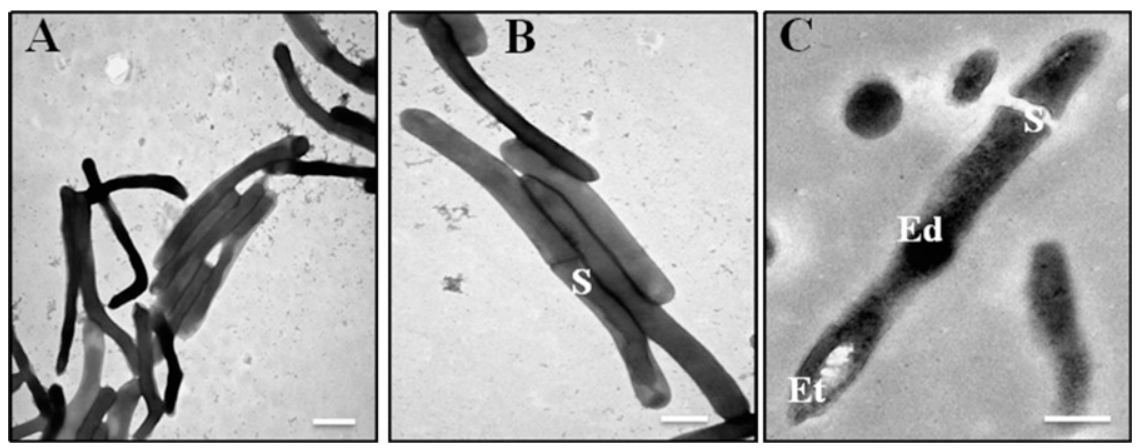

Fig. 1. Cell morphology for internal ultrastructure of GXBZ01 under the transmission electron microscopy after negatively staining with $1 \%$ phosphotungstic acid. A, The coryneform and ' $V$ ' shape. B, The formation of septum $(S)$ in cell ( $b a r=0.5 \mu \mathrm{m})$. C, The internal ultrastructure of GXBZ01 cell reveals the presence of electron transparency (Et), electron dense (Ed), and septum (S) parts $($ bar $=0.2 \mu \mathrm{m})$. 
LxxCTCB07 and LxxGXBZ01 in 13 SNPs, including three synonymous mutations, two nonsynonymous mutations, and eight indels consisting of two insertions and six deletions. Two indels were found in the coding sequence, which might cause frame shifting. The sequence analysis also showed that the SNPs and indels were associated with genes coding $\alpha$-amylase, DNA repair helicase, ATPdependent $\mathrm{Clp}$, protease, ATP-binding subunit, 50S ribosomal protein L9, oxidoreductase, and hypothetical proteins. The difference of Lxx09155 protein sequences between LxxCTCB07 and LxxGXBZ01 was that isoleucine was replaced by valine on the 175th site within an ALA-rich site and the altered amino acids were still neutral, nonpolar, and hydrophobic. The difference of Lxx25150 protein sequences between the two strains was that lysine was replaced by glutamate on the 45th site within an amidation site. Lysine, with a positive charge, was alkaline and hydrophilic, and glutamate, with a negative charge, was acidic and hydrophilic; also, the analysis with ExPASy showed that the mutation caused an isoelectric point decrease but the protein was still alkaline. Lxx13110 presented a nucleic acid insertion with $G$ on the 362th site of the DNA sequence that caused frameshift mutation, resulting in a protein sequence change. The analysis of protein sequence with the Motif scan showed that the myristyl site increased by 1 , the PKC phospho site disappeared and the CK2 phospho site appeared by 2. Lxx24120 presented nucleic acids deletion with $\mathrm{G}$ on the 68 th site that caused frameshift mutation, resulting in a protein sequence change. The analysis of protein sequence with the Motif scan showed that the cAMP phospho site increased by 1 , the CK2 phospho site increased by 1 , the myristyl site increased by 2 , and the PKC phosoho site increased by 2 ; amidation, ATP-GTP-A, and MH2 sites appeared, but the NLS-BP site disappeared. Five variations (four SNPs and one indel) were selected for experimental validation, using the Sanger platform, and only one of the mutations (Lxx17950) could not be determined.

LXXGXBZ01 colonization and its effects on vascular ultrastructure of sugarcane stalk. Under SEM, horizontal and vertical sections from an internode of healthy sugarcane stalk showed that no bacterial cells were observed in the mature healthy cane (Fig. $2 \mathrm{~A}$ and $\mathrm{B})$. Bacterial colonization was found in pits and on the surface of the secondary wall in the vertical section of vessel elements of L. xyli subsp. xyli-infected sugarcane stalk (Fig. $2 \mathrm{C}$ to F).

Table 1. Sequencing statistical data for the Leifsonia xyli subsp. xyli LxxGXBZ01, as aligned with the LxxCTCB07 sequence

\begin{tabular}{|c|c|c|}
\hline \multicolumn{3}{|c|}{ Sequencing statistics of LxxGXBZ01 } \\
\hline Insert size (bp) & \multicolumn{2}{|c|}{500} \\
\hline Reads length (bp) & \multicolumn{2}{|c|}{$90: 90$} \\
\hline Raw data $(\mathrm{Mb})$ & \multicolumn{2}{|c|}{292} \\
\hline Adapter (\%) & \multicolumn{2}{|c|}{0.03} \\
\hline Duplication (\%) & \multicolumn{2}{|c|}{0.45} \\
\hline Total reads & \multicolumn{2}{|c|}{$3,242,504$} \\
\hline Filtered reads $(\%)$ & \multicolumn{2}{|c|}{10.22} \\
\hline Low quality filtered reads $(\%)$ & \multicolumn{2}{|c|}{5.42} \\
\hline Clean data $(\mathrm{Mb})$ & \multicolumn{2}{|c|}{262} \\
\hline \multicolumn{3}{|c|}{ Depth and coverage of sequence } \\
\hline Sample name & \multicolumn{2}{|c|}{ LxxGXBZ01 } \\
\hline Reference name & \multicolumn{2}{|c|}{ LxxCTCB07 } \\
\hline Reference size (bp) & \multicolumn{2}{|c|}{$2,584,158$} \\
\hline Covered length (bp) & \multicolumn{2}{|c|}{$2,583,939$} \\
\hline Coverage $(\%)$ & \multicolumn{2}{|c|}{99.99} \\
\hline Average depth & \multicolumn{2}{|c|}{130} \\
\hline Assembly statistics & Scaffold & Contig \\
\hline Total number & 82 & 2,724 \\
\hline Total length (bp) & $2,446,908$ & $2,243,293$ \\
\hline N50 (bp) & 53,480 & 1,088 \\
\hline N90 (bp) & 15,639 & 405 \\
\hline Maximum length (bp) & 190,156 & 4,709 \\
\hline Minimum length (bp) & 559 & 200 \\
\hline $\mathrm{G}+\mathrm{C}$ contents $(\%)$ & 67.94 & 67.94 \\
\hline
\end{tabular}

Moreover, many small granular substances adhering to the wall were observed in reticulate vessels (Fig. 2D).

Further anatomical observation on the healthy, hot water-treated and L. $x y l i$ subsp. $x y l i$-infected stalks found that the anatomical structures of both healthy and hot water-treated sugarcane internodes were the same, the cell walls were uniform in thickness and tightly packed, and the cells were arranged in uniform rows without sticky substances inside the cells (Fig. 3A). On the contrary, the walls of the vessel element in L. $x y l i$ subsp. $x y l i$-infected stalks showed various anatomical changes, including uneven thickness of the cell wall, deformation, cell decomposition, and ED substance accumulation inside the cells (Fig. 3B).

Effect of $L$. xyli subsp. xyli on endogenous hormone contents in sugarcane. The contents of endogenous hormones were different among plants in the three treatments at different growth stages (Fig. 4). The patterns of IAA changes were similar in all three treatments in both sugarcane 'ROC22' (Fig. 4A) and 'Badila' (Fig. 4B), increasing slightly from 90 to 120 days, and then, decreasing significantly from 120 until 180 days. Compared with the healthy and HWT, the IAA contents in the L. xyli subsp. xyli-infected plants were obviously lower throughout the entire growth period. There was no statistical difference between the healthy and HWT.

The $\mathrm{GA}_{3}$ contents were not statistically different among the three treatments from 90 to 150 days after shoot emergence; however, at 180 days, the $\mathrm{GA}_{3}$ contents were significantly lower in the $L$. xyli subsp. xyli-infected treatment than in the healthy and HWT for both varieties (Fig. 4C and D). The decreases of $\mathrm{GA}_{3}$ were $23.5 \%$ in 'ROC22' and $21.2 \%$ in 'Badila', as compared with that in the healthy treatment. Both varieties showed similar patterns and there was no difference between the $\mathrm{GA}_{3}$ contents in the healthy and HWT.

In contrast to IAA content, the ABA displayed an increase in concentration from 120 to 180 days in all three treatments for both varieties (Fig. 4E and F). Moreover, the ABA contents at both 150 and 180 days were significantly higher in the $L$. xyli subsp. xyli-infected treatment than in the healthy and HWT for both varieties. However, the two sugarcane varieties showed different patterns of ABA level in different treatments, i.e., obviously higher in the L. xyli subsp. $x y l i-$ infected treatment than in the healthy and HWT from 90 to 180 days in 'ROC22' (Fig. 4E) while there was no significant difference at 90 and 120 days between the treatments in 'Badila' (Fig. 4F). There was also no significant difference in the ABA content between the healthy and HWT during the experiment.

\section{Discussion}

In this study, we isolated a $L$. xyli subsp. xyli strain, LxxGXBZ01, from $L$. $x y l i$ subsp. xyli-infected cane stalk of sugarcane 'Badila' and observed the bacterium colonized in xylem elements of sugarcane stalk under TEM and SEM; we resequenced the genome DNA of L. xyli subsp. xyli and found that LxxGXBZ01 shared $99.99 \%$ sequence homology with LxxCTCB07 from Brazil, which is the first study to compare two L. xyli subsp. xyli strains using whole-genome sequencing technology. We also inoculated $L$. xyli subsp. xyli into sugarcane plants and found that the cell wall in $L$. $x y l i$ subsp. $x y l i$-infected stalks was distorted and full of ED substances and the IAA and $\mathrm{GA}_{3}$ contents were significantly lower while ABA content was significantly higher in $L$. xyli subsp. xyli-infected sugarcane stalk. The information obtained in this study will expand our understanding of ratoon stunt etiology as well as cytological and physiological bases of the disease manifestation.

Young et al. (2006) collected 105 DNA isolates from nine countries, including Australia, Indonesia, Japan, the United States, Brazil, Mali, Zimbabwe, South Africa, and France (Reunion), and then analyzed the $16 \mathrm{~S}$ ribosomal RNA gene and DNA fingerprinting to assess $L$. xyli subsp. xyli genetic diversity. Their results showed no sequence variation and indicated that a single pathogenic clone occurred in these nine countries. The results of the genome sequencing in this study have revealed that strain LxxGXBZ01 is essentially identical with LxxCTCB07. Among the differences in SNPs and indels, six SNPs and two indels found in the coding sequences suggested that they were predicted to encode genes. Bioinformatic analysis found that the proteins encoded by the mutant genes were 
involved in DNA replication, protein metabolism, and sugar metabolism (Kengen et al. 1996; Hung et al. 1998; Porankiewicz et al. 1999; Flores et al. 2004; Naganathan and Moore 2013). The changes of nucleotide sequences caused changes in protein sequences; especially, frameshift mutations caused many protein sequence changes. However, the functions of these proteins related to LxxGXBZ01 pathogenicity remain unknown. The ANI between isolates LxxGXBZ01 and LxxCTCB07 was $93.61 \%$, indicating that they should belong to the same species (Zhang et al. 2014).

We observed the L. xyli subsp. xyli on the secondary wall of xylem vessel elements, under SEM, and found that, in the L. xyli subsp. xyliinfected sugarcane, the cell wall of vessel elements was degraded with bacterium growth. Besides the bacteria present in the xylem vessel, we also observed many circular and granular, ED, and sticky substances in vessel elements in the $L$. xyli subsp. xyli-infected sugarcane. Though these substances were not yet identified, they could be pectins, tyloses, or gums produced by the plant in response to bacterium or phytoxins produced by the bacterium; the results confirmed that L. xyli subsp. xyli caused not only plugging of vascular cells but also cellwall degradation. It has been reported that the main cause of the growth reduction associated with ratoon stunt was due to the physical plugging of xylem vessels (Gillaspie et al. 1973). Xylem vessels become occluded with pectins, tyloses, and gums produced by the plant in response to invasion by the bacterium (Stevenson et al. 2004) or phytoxins produced by bacteria (Lee et al. 1982).

In most plants, the vascular system helps to distribute water and nutrients from the roots to the leaves, and blockage by mucilaginous substance of vascular cells will restrict water and nutrient transportation. The current study also supports that the distribution of water and nutrients may be restricted in L. xyli subsp. xyli-infected sugarcane (Kao and Damann 1980). The genome sequence of $L$. xyli subsp. xyli revealed many pseudogenes involved in the degradation of polysaccharides, uptake of free sugars, synthesis of amino acids, lateral transfer, and genes functioning for cellulase, pectinase, wilt-inducing protein, lysozyme, and desaturase, which might relate to vascular cell-wall decomposition, transport restriction of water and nutrients, and consequently, stalk growth stunting, if those genes function (Monteiro-Vitorello et al. 2004).

Plant growth not only depends on water and nutrition but also is regulated by the content and balance of plant hormones. The contents of ABA, a hormone widely reported as a growth inhibitor and a stress hormone, were significantly higher in the L. xyli subsp. xyli-infected sugarcane stalk than those in the healthy and HWT stalks in this study, suggesting that sugarcane plants under pathogen stress produce $\mathrm{ABA}$. It has been reported that $\mathrm{ABA}$ plays important roles in
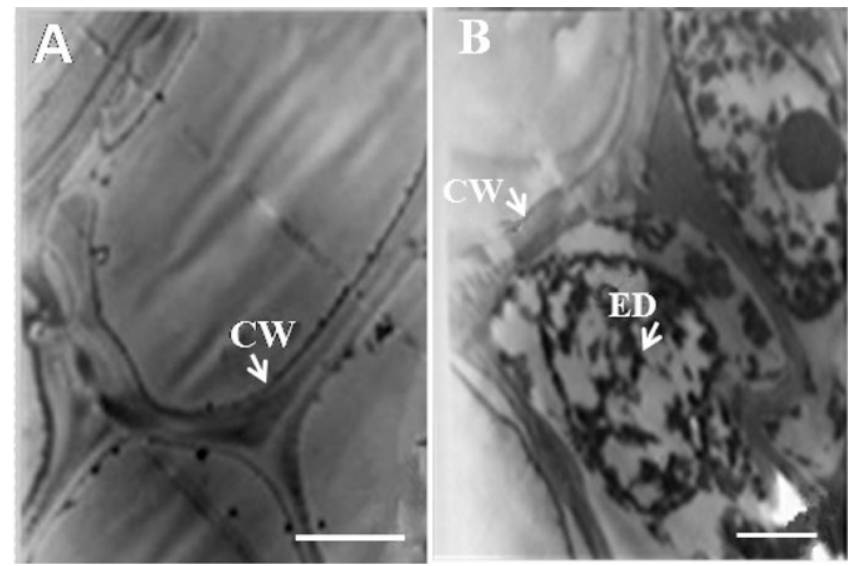

Fig. 3. Anatomical changes of the vascular elements in the LxXGXBZ01-infected stalk as compared with the healthy stalk in a cross section for sugarcane variety Badila under a transparent transmission electron microscope. A, Healthy sugarcane stalk with the uniform thickness in cell walls, which were tightly packed and were arranged in neat rows without extra substances to fill the inside of the cells (bar = $5 \mu \mathrm{m})$. B, The cell wall of Leifsonia xyli subsp. xyli-infected sugarcane stalk was fractured and detached, with more electron-dense substances accumulated inside of the cells $(\mathrm{bar}=2 \mu \mathrm{m})$.
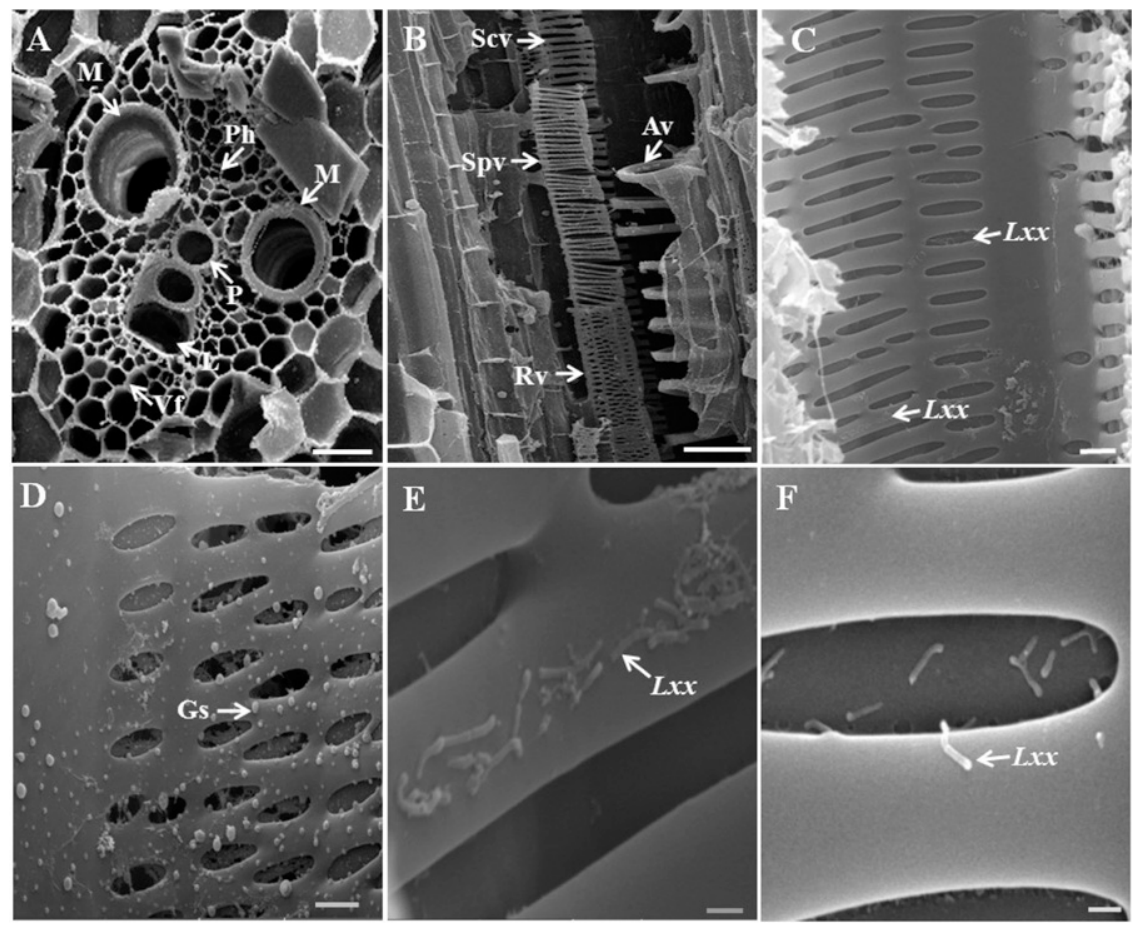

Fig. 2. Ultrastructure of vascular bundle in the cane internodes of healthy and LxXGXBZ01-infected stalks in sugarcane variety Badila under scanning electron microscope (SEM), showing various types of colonization in the vascular bundle after LxXGXBZ01 infection. A, Cross section of vascular bundle in healthy sugarcane stalk, consists of metaxylem (M), protoxylem $(\mathrm{P})$, phloem, lacuna $(\mathrm{Ph})$, and many vascular fibroblasts $(\mathrm{Vf})(\mathrm{bar}=50 \mu \mathrm{m})$. B, Vertical section of four types of xylem vessel, including annular (Av), scalariform (Scv), spiral (Spv), and reticulate vessel (Rv), in healthy sugarcane stalk $(\mathrm{bar}=50 \mu \mathrm{m}), \mathbf{C}, \mathbf{D}, \mathbf{E}$, and F, Colonization in vascular bundle of infected sugarcane stalk. C, Vertical section of a scalariform vessel with LxXGXBZ01 colonization in pits and cell walls $(\mathrm{bar}=10 \mu \mathrm{m})$. D, Many small granular substances $(\mathrm{Gs})$ existed in the pits and wall of the reticulate vessel (bar $=5 \mu \mathrm{m})$. E, LxXGXBZ01 colonization on the cell wall of the scalariform vessel (bar $=1 \mu \mathrm{m})$. F, LxXGXBZ01 colonization in pits $($ bar $=1 \mu \mathrm{m})$. 
plant defense responses in Arabidopsis thaliana (Adie et al. 2007), tomato (Solanum lycopersicum) (Asselbergh et al. 2008), and rice (Oryza sativa) (De Vleesschauwer et al. 2012). However, the role of $\mathrm{ABA}$ in plant defense appears to be complex and depends on the type of pathogen and plant involved. Being the hormone with a very large variation in content in response to $L$. xyli subsp. xyli infection, it warrants further investigation, as it may provide more mechanistic insights into ratoon stunt pathogenesis.

A

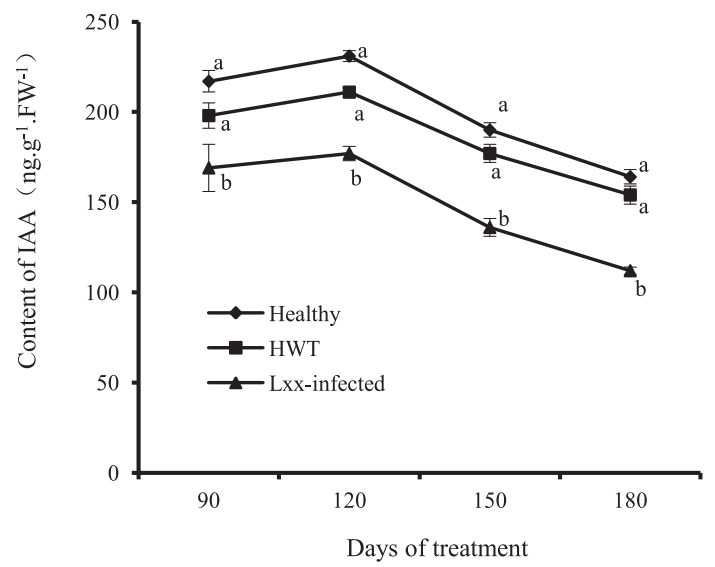

C

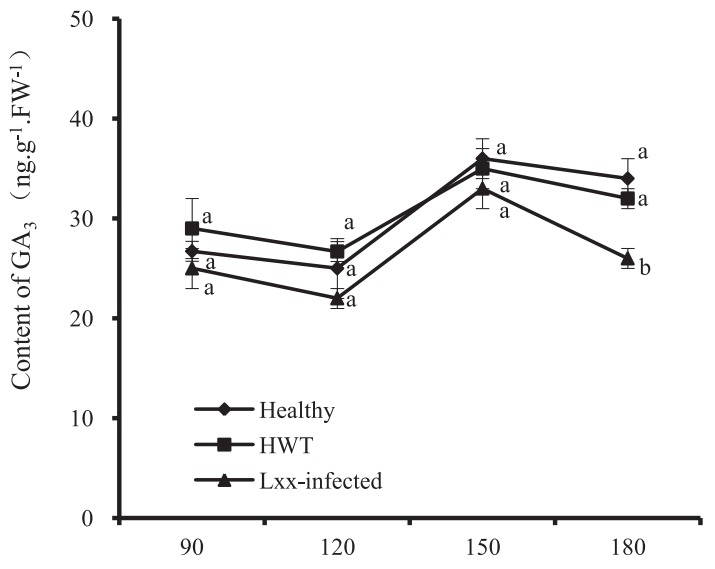

Days of treatment

$\mathbf{E}$

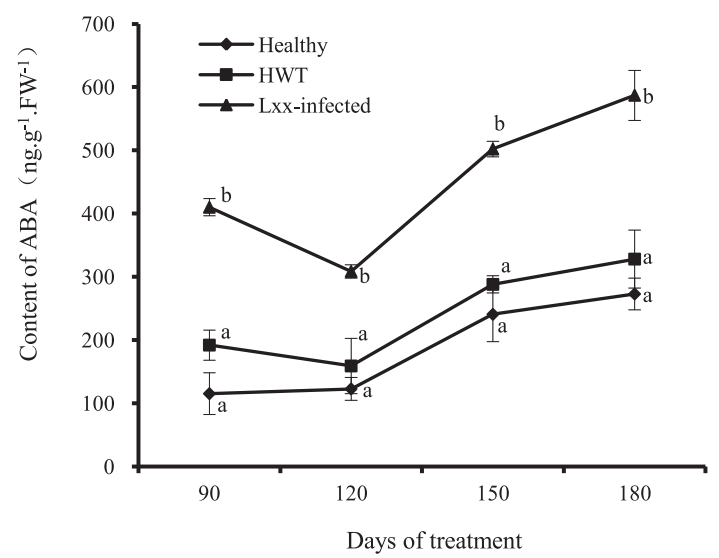

The results of the study demonstrated that pathogen L. xyli subsp. $x y l i$ interferes with sugarcane growth not only by stimulating the production of ABA but, also, by inhibiting the production of IAA (auxin) in plants. Auxin has been implicated primarily in plant growth and development processes, including tropisms, root and shoot architecture, flower and fruit development, vascular formation, tissue differentiation, and cell elongation. Therefore, precise auxin levels are vitally important to plants, which have many mechanisms to maintain

B

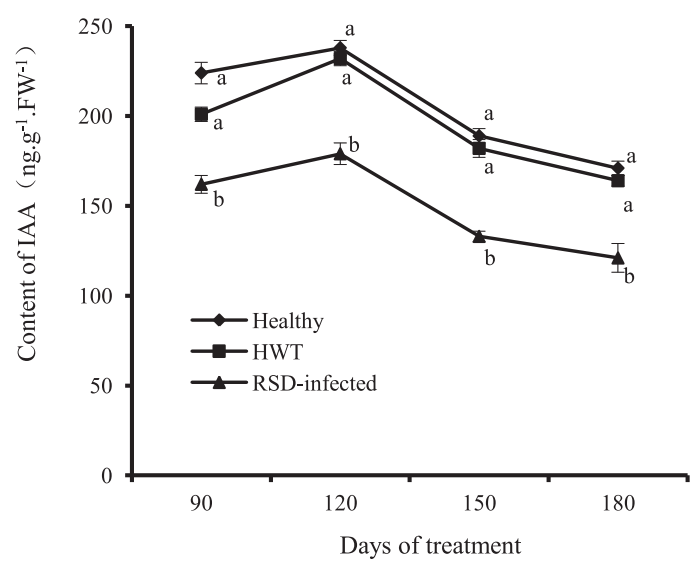

D

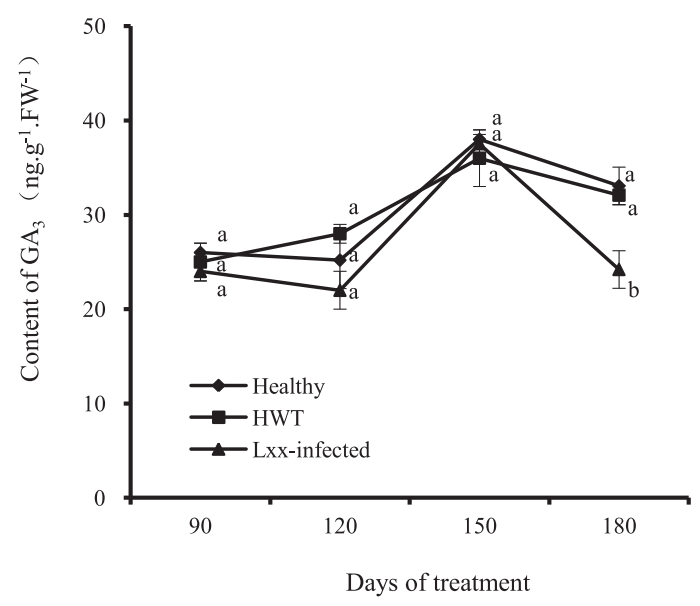

$\mathbf{F}$

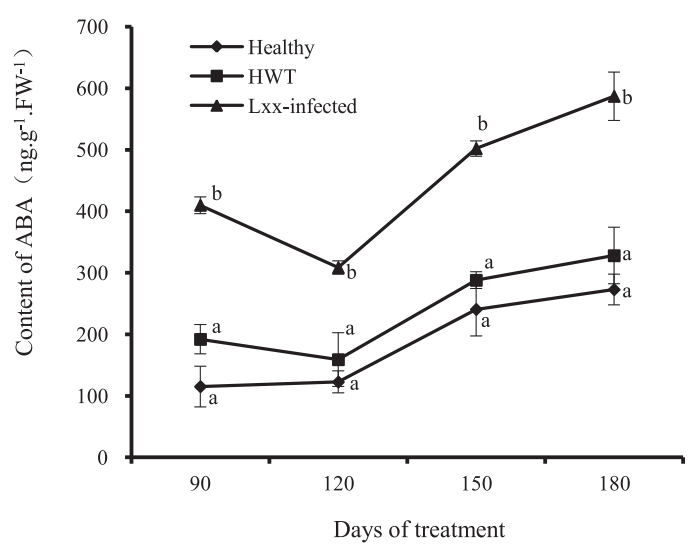

Fig. 4. The contents of (indoleacetic acid, IAA), gibberellic acids $\left(G_{3}\right)$, and abscisic acid (ABA) in the sugarcane stalk in three different seedcane treatments: (i) healthy (Leifsonia xyli subsp. xyli-free), (ii) hot water treated (HWT), and (iii) L. xyli subsp. xyli-infected seedcanes from 90 to 180 days after shoot emergence. Data points with different letters are significantly different $(P<0.05)$ between different treatments at the same time. A, IAA content in 'ROC22'; B, IAA content in 'Badila'; C, GA 3 content in 'ROC22'; D, GA 3 content in 'Badila'; E, ABA content in 'ROC22'; and F, ABA content in 'Badila'. 
auxin homeostasis. Some recent studies on plant-pathogen interactions identify auxin as a key component of pathogenesis and plant defense (Fu and Wang 2011; Ghanashyam and Jain 2009). Auxin can loosen the plant cell wall (Lindow and Brandl 2003) and promotes cell expansion through the expression of expansins (McQueen-Mason and Cosgrove 1995). In this study, the levels of endogenous IAA were observed to be significantly less in $L$. xyli subsp. xyli-infected sugarcane. Therefore, a low concentration of IAA might associate with short and thin internodes and reduced plant growth.

$\mathrm{GA}_{3}$ has been known to control plant height (Tanimoto 2012). In our previous study, it was found that exogenously applied $\mathrm{GA}_{3}$ promotes the elongation of the top stalk in sugarcane (Wu et al. 2009). In this study, the level of endogenous $\mathrm{GA}_{3}$ in $L$. xyli subsp. xyli-infected plants was lower than that in healthy plants at the late growth stage (180 days) but no significant differences were observed between treatments from 90 to 150 days of plant growth, which suggests that $L$. xyli subsp. $x y l i$-infection reduces $\mathrm{GA}_{3}$ levels in sugarcane more seriously at the late growth stage than at early growth stage. Our finding is consistent with the report in rice infected with the rice dwarf virus, which showed a reduced level of endogenous $\mathrm{GA}_{3}$ as compared with the healthy plants (Zhu et al. 2005). However, $\mathrm{GA}_{3}$ moderates plant defense responses and interacts with $\mathrm{ABA}$ and IAA, so its role in ratoon stunt pathology, though not evident here, needs further research.

In sugarcane fields, the stunting is often not uniform and plants in L. $x y l i$ subsp. $x y l i$-infected fields often have a characteristic uneven appearance (Tiwari et al. 2012). The greenhouse experiments were conducted in pots with no water and nutrition stress, and the changes of anatomical structure, metabolisms, and plant height in L. xyli subsp. xyli-infected sugarcane could be due to pathogenesis (Stitt et al. 2010). In this study, the levels of ABA, IAA, and $\mathrm{GA}_{3}$ in the HWT plants, which were free from $L$. xyli subsp. xyli, were not significantly different from the healthy ones, which indicates that HWT is an effective way to control sugarcane ratoon stunt (Li et al. 2009).

Identification and quantitative determination of specific disease effects on the physiology and anatomy of affected plants are the essential first steps for broader understanding of disease damage and crop yield losses (Bastiaans et al. 1994; Zhao et al. 2011). This study revealed the cytological and physiological mechanisms associated with the damage in $L$. xyli subsp. xyli-infected sugarcane. Another important outcome of the study is the finding that the Chinese isolate of $L$. xyli subsp. xyli is identical to other strains collected from very different geographic locations. Collectively, the results presented here could improve our understanding of ratoon stunt etiology as well as cytological and physiological aspects of sugarcane's response to ratoon stunt.

\section{Acknowledgments}

The authors thank R. Kumar Singh for reviewing the manuscript and $\mathrm{H} . \mathrm{Li}$ for technical assistance. This work was supported by Natural Science Fund (31360293), Guangxi Natural Science Fund (2012GXNSFDA053011), International Cooperation Program Project of China (2013DFA31600), China 863 Program (2013AA102604), Guangxi Special Funds for Bagui Scholars and Distinguished Experts and Guangxi R \& D Program Funding (GKG1222009-1B, GKN14121008-2-1).

\section{Literature Cited}

Adie, B. A. T., Pérez- Pérez, J., Pérez-Pérez, M. M., Godoy, M., Sánchez-Serrano, J. J., Schmelz, E. A., and Solano, R. 2007. ABA is an essential signal for plant resistance to pathogens affecting JA biosynthesis and the activation of defenses in Arabidopsis. Plant Cell 19:1665-1681.

Asselbergh, B., De Vleesschauwer, D., and Höfte, M. 2008. Global switches and fine-tuning-ABA modulates plant pathogen defense. Mol. Plant-Microbe Interact. 21:709-719.

Bastiaans, L., Rabbinge, R., and Zadoks, J. C. 1994. Understanding and modeling leaf blast effects on crop physiology and yield. Pages 357-380 in: Rice Blast Disease. R. S. Zeigler, S. A. Leong, and P. S. Teng, eds. CAB International, Wallingford, UK.

Brumbley, S. M., Petrasovits, L. A., Birch, R. G., and Taylor, W. J. 2002. Transformation and transposon mutagenesis of Leifsonia xyli subsp. xyli, causal organism of ratoon stunting disease of sugarcane. Mol. Plant-Microbe Interact. 15:262-268

Comstock, J. C. 2002. Ratoon stunting disease. Sugar Tech 4:1-6.
Comstock, J. C. 2008. Sugarcane yield loss due to ratoon stunt. J. Am. Soc. Sugar Cane Technol. 28:22-31.

Davis, M. J., Gillaspie, A. G., Jr., Harris, R. W., and Lawson, R. H. 1980. Ratoon stunting disease of sugarcane: Isolation of the causal bacterium. Sci. 210: 1365-1367.

De Vleesschauwer, D., Van Buyten, E., Satoh, K., Balidion, J., Mauleon, R., Choi, I. R., Vera-Cruz, C., Kikuchi, S., and Höfte, M. 2012. Brassinosteroids antagonize gibberellin and salicylate-mediated root immunity in rice. Plant Physiol. 158:1833-1846.

Dean, J. L. 1983. Single-stool plots for estimating relative yield losses caused by ratoon stunting disease of sugarcane in Florida. Plant Dis. 67:47-49.

Flores, M. J., Bidnenko, V., and Michel, B. 2004. The DNA repair helicase UvrD is essential for replication fork reversal in replication mutants. EMBO Rep. 5:983-988.

$\mathrm{Fu}$, J., and Wang, S. P. 2011. Insights into auxin signaling in plant-pathogen interactions. Front. Plant Sci. 74:00074.

Ghai, M., Singh, V., Martin, L. A., McFarlane, S. A., Antwerpen, T., and Rutherford, R. S. 2014. A rapid and visual loop-mediated isothermal amplification assay to detect Leifsonia xyli subsp. xyli targeting a transposase gene. Lett. Appl. Microbiol. 59:648-657.

Ghanashyam, C., and Jain, M. 2009. Role of auxin-responsive genes in biotic stress responses. Plant Sig. Behav. 4:846-848.

Gillaspie, A. G., Jr., Davis, R. E., and Worley, J. F. 1973. Diagnosis of ratoon stunting disease based on the presence of a specific micro-organism. Plant Dis. Rep. 57:987-990.

Gillaspie, A. G., Jr., and Teakle, D. S. 1989. Ratoon stunting disease. Pages 59-80 in: Disease of Sugarcane. C. Ricaud, B. T. Egan, A. G. Gillaspie, and C. G. Hughes, eds. Elsevier, Amsterdam.

Grisham, M. P. 1991. Effect of ratoon stunting disease on yield of sugarcane grown in multiple three-year plantings. Phytopathothogy 81:337-340.

Hoy, J. W., and Flynn, J. L. 2001. Control of ratoon stunting disease of sugarcane in Louisiana with seedcane produced through micropropagation and resistant cultivars. Proc. Int. Soc. Sugar Cane Technol. 24:417-421.

Hoy, J. W., and Grisham, M. P. 2006. Effects of harvester type, inoculums source, and cultivar on spread of ratoon stunting disease. Sugar Cane Int. 24:10-14.

Hung, L. W., Wang, I. X., Nikaido, K., Liu, P. Q., Ames, G. F. L., and Kim, S. H 1998. Crystal structure of the ATP-binding subunit of an ABC transporter. Nature 396:703-707.

Kao, J., and Damann, K. E., Jr. 1980. In situ localization and morphology of the bacterium associated with ratoon stunting disease of sugarcane. Can. J. Bot. 58:310-315.

Kengen, S. W. M., Stams, A. J. M., and de Vos, W. M. 1996. Sugar metabolism of hyperthermophiles. FEMS Microbiol. Rev. 18:119-137.

Lee, R. F., Raju, B. C., Nyland, G., and Goheen, A. C. 1982. Phytotoxin(s) produced in culture by the Pierce's disease bacterium. Phytopathology 72: 886-888

Li, W. F., Huang, Y. K., Fan, Y. H., Li, J., Lu, W. J., Wu, Z. K., Luo, Z. M., and Yang, H. C. 2009. Study on bacteria-free test of sugarcane ratoon stunting disease by hot-water. Southwest China. J. Agric. Sci. 22:343-347.

Li, W. F., Shen, K., Huang, Y. K., Wang, X. Y., Yin, J., Luo, Z. M., and Shan, H. L. 2014. Incidence of sugarcane ratoon stunting disease in the major cane growing regions of China. Crop Prot. 60:44-47.

Lindow, S. E., and Brandl, M. T. 2003. Microbiology of the phyllosphere. Appl. Environ. Microbiol. 69:1875-1883.

Matsubayashi, Y., Morita, A., Matsunaga, E., Furuya, A., Hanai, N., and Sakagami, Y. 1999. Physiological relationship between auxin, cytokinin, and a peptide growth factor, phytosulfokinea, in stimulation of asparagus cell proliferation. Planta 207:559-565.

McQueen-Mason, S. J., and Cosgrove, D. J. 1995. Expansin mode of action on cell walls (analysis of wall hydrolysis, stress relaxation, and binding). Plant Physiol. 107:87-100.

Monteiro-Vitorello, C. B., Camargo, L. E. A., van Sluys, M. A., Kitajima, J. P., Truffi, D., Amaral, A. M., Harakava, R., Oliveira, M. C., Miyaki, C., Takita, M. A., da Silva, A. C., Furlan, L. R., Carraro, D. M., Camarotte, G., Almeida, N. F., Carrer, H., Jr., Coutinho, L. L., El-Dorry, H. A., Ferro, M. I., Gagliardi, P. R., Giglioti, E., Goldman, M. H., Goldman, G. H., Kimura, E. T., Ferro, E. S., Kuramae, E. E., Lemos, E. G., Lemos, M. V., Mauro, S. M., Machado, M. A., Marino, C. L., Menck, C. F., Nunes, L. R., Oliveira, R. C., Pereira, G. G., Siqueira, W., de Souza, A. A., Tsai, S. M., Zanca, A. S., Simpson, A. J., Brumbley, S. M., and Setúbal, J. C. 2004. The genome sequence of the gram-positive sugarcane pathogen Leifsonia xyli subsp. xyli. Mol. Plant-Microbe Interac. 17:827-836.

Naganathan, A., and Moore, S. D. 2013. Crippling the essential GTPase Der causes dependence on ribosomal protein L9. J. Bacteriol. 195:3682-3691.

Pan, Y. B., Grisham, M. P., Burner, D. M., Damann, K. E., and Wei, Q. 1998. A polymerase chain reaction protocol for the detection of Clavibacter xyli subsp. xyli, the causal bacterium of ratoon stunting disease. Plant Dis. 82: 285-290.

Pelosi, C. S., Lourenço, M. V., Silva, M., Santos, A. Z., França, S. C., and Marins, M. 2013. Development of a Taqman real-time PCR assay for detection of Leifsonia xyli subsp. xyli. Trop. Plant Pathol. 38:343-345.

Porankiewicz, J., Wang, J., and Clarke, A. K. 1999. New insights into the ATPdependent Clp protease: Escherichia coli and beyond. Mol. Microbiol. 32 449-458. 
Robert-Seilaniantz, A., Navarro, L., Bari, R., and Jones, J. D. 2007. Pathological hormone imbalances. Curr. Opin. Plant Biol. 10:372-379.

Rossler, L. A. 1974. The effects of ratoon stunting disease on three sugarcane varieties under different irrigation regimes. Proc. of the International Society of Sugar Cane Technologists 15:250-257.

Sheng, F. K., Chen, Z. H., Yang, S. R., and Deng, H. H. 2008. Control effects of hot water treatment on sugarcane ratoon stunting disease by and its influence on regenerative plants. Yunnan Nong Ye Da Xue Xue Bao 23:476-478.

Stevenson, J. F., Matthews, M. A., Greve, L. C., Labavitch, J. M., and Rost, T. L. 2004. Grapevine susceptibility to Pierce's disease I: Relevance of hydraulic architecture. Am. J. Enol. Vitic. 55:228-237.

Stitt, M., Sulpice, R., and Keurentjes, J. 2010. Metabolic networks: How to identify key components in the regulation of metabolism and growth. Plant Physiol. 152:428-444.

Tanimoto, E. 2012. Tall or short? Slender or thick? A plant strategy for regulating elongation growth of roots by low concentrations of gibberellins. Ann. Bot. (Lond.) 110:373-381.

Tiwari, A K., Vishwakarma, S. K., Pandey, N., and Lal, M. 2012. Ratoon stunting disease (Leifsonia xyli) of sugarcane. Plant Knowl. J. 1:20-24.

Wu, C. F., and Huang, M. Q. 1986. Ratoon stunting disease in sugarcane was found in mainland China. Sugarcane and Cane Sugar 3:29-30.

Wu, J. M., Li, Y. R., Yang, L., Wang, A. Q., and Yang, L. T. 2009. Relationship between gibberellin-induced internode elongation and endogenous hormone changes in sugarcane. Chin. J. Trop. Crop. 30:1452-1457.

Yang, D. L., Yao, J., Mei, C. S., Tong, X. H., Zeng, L. J., Li, Q., Xiao, L. T., Sun, T. P., Li, J. G., Deng, X. W., Lee, C. M., Thomashow, M. F., Yang, Y. N., He,
Z. H., and He, S. Y. 2012. Plant hormone jasmonate prioritizes defense over growth by interfering with gibberellin signaling cascade. Proc. Natl. Acad. Sci. U.S.A. 109:E1192-E1200.

Yang, J., Zhang, J., Wang, Z., Zhu, Q., and Wang, W. 2001. Hormonal changes in the grains of rice subjected to water stress during grain filling. Plant Physiol. 127:315-323.

Young, A. J., Nock, C. J., Martin, A., and Ensbey, M. 2014. Novel diagnostic method for ratoon stunting disease: Development and implications for ratoon stunt management. In Proceedings of the 36th Conference of the Australian Society of Sugar Cane Technologists held at Gold Coast, Queensland, Australia, 29 April-1 May, 2014. Australian Society of Sugar Cane Technologists.

Young, A. J., Petrasovits, L. A., Croft, B. J., Gillings, M., and Brumbley, S. M. 2006 Genetic uniformity of international isolates of Leifsonia xyli subsp. xyli, causal agent of ratoon stunting disease of sugarcane. Australas. Plant Pathol. 35:503-511.

Zhang, W., Du, P. C., Zheng, H., and Chen, C. 2014. Whole-genome sequence comparison as a method for improving bacterial species definition. J. Gen. Appl. Microbiol. 60:75-78

Zhao, D. L., Glynn, N. C., Glaz, B., Comstock, J. C., and Sood, S. 2011. Orange rust effects on leaf photosynthesis and related characters of sugarcane. Plant Dis. 95:640-647.

Zhu, S. F., Gao, F., Cao, X. S., Chen, M., Ye, G. Y., Wei, C. H., and Li, Y. 2005. The rice dwarf virus $\mathrm{P} 2$ protein interacts with ent-kaurene oxidases in vivo, leading to reduced biosynthesis of gibberellins and rice dwarf symptoms. Plant Physiol. 139:1935-1945.

Zwieniecki, M. A., Orians, C. M., Melcher, P. J., and Holbrook, N. M. 2003. Ionic control of the lateral exchange of water between vascular bundles in tomato. J. Exp. Bot. 54:1399-1405. 